\title{
Variation in Caste Homophily Across Villages and Contexts in Rural India
}

\author{
Tom Davidson \\ Department of Sociology, \\ Cornell University \\ trd54@cornell.edu
}

\section{Introduction}

This paper focuses on caste homophily across seventy-five villages in rural Karnataka, India. Caste is conceptualized as a system of ethnic categories that map onto positions within the social structure of each village. Despite being a salient category across India, the caste structure is not uniform across villages, caste groups or network contexts. Building in particular on the work of Brubaker (2004; 2015) and Wimmer (2008; 2013) this paper focuses on the extent to which the level of caste homophily fluctuates across these dimensions.

I use social network and demographic data collected by Banerjee et al. (2013). Using a measure of homophily defined by James Coleman (1958) and refined by Bojanowski and Corten (2014) I observe the level of caste homophily for low and high caste groups for eight different types of relation within each village. Overall there is strong caste homophily across the majority of contexts; people tend to exchange resources and socialize with other people occupying a similar position in the caste order. Nonetheless the level of homophily varies across villages, relations, and groups. It appears to be 
strongest among higher caste groups, although it weakens with regards to the lending and borrowing of money, a vertical relationship between high and low castes. The lending of rice and kerosene and social relationships involving advice giving and important decisions are particularly homophilous for both groups. I use OLS regression to assess the correlates on homophily, finding that the proportion of low caste groups, village natives, and access to electricity are significant predictors of the level of homophily. While causality remains undetermined, the findings suggest that further research is necessary to understand the effects of caste homophily and the factors that contribute to perpetuating the caste order.

\section{Literature review}

\subsection{Social networks and ethnic homophily}

Homophily - the tendency for similar individuals to associate with one another - is one of the most enduring features of social networks. Homophily occurs based on many factors including sex, gender, race, ethnicity, age, attitudes, beliefs, and behaviors. Numerous potential causal mechanisms exist that may contribute to this phenomenon: similar people are often geographically close, members of the same organizations, kinship groups, and positions in social networks (McPherson, Smith-Lovin and Cook 2001). Marsden argues that strong homophily implies the presence of stratification and social closure; the concomitant the low frequency of cross-group relations signals a lack of social integration (1998: 58). In this paper I focus on ethnic homophily, the tendency for members of an ethnic category to associate with one another and prefer such associations over those to members of other 
ethnic categories. I use Andreas Wimmer's definition of ethnicity as "a subjectively felt sense of belonging based on the belief in shared culture and common ancestry" (2008: 973). I study the case of the Indian caste order and treat each caste category as an ethnic group ${ }^{1}$. I discuss the topic of ethnic homophily in general before focusing on caste in more detail.

Wimmer (2013) argues that there are four types of tie-generating mechanisms that can explain ethnic homophily. The first is "availability"; people's social relationships are limited to the set of people with whom they can potentially intercourse. If the relative size of a group is small then it is more likely that its members will form out-group ties. Measures of homophily, including the one I use below, must therefore distinguish between availability and homophily. Second, is "propinquity", individuals are more likely to form ties if they are regularly spatially proximate (Festinger, Schachter, and

\footnotetext{
${ }^{1}$ Some people may disagree with this classification, as Indians can also be members of other ethnic groups that fit this definition. For example, ethnicity may be related to religion, as Hindu and Muslim, to region, as Kashmiri and Punjabi, or to language, as Tamil or Telugu speakers. Ethnicities are often "nested" (Wimmer 2008: 23); like a matryoshka doll, the same person can be an Indian citizen, a resident of Karnataka, a Malayalam speaker, a follower of Hinduism, a devotee of Ganesha, a member of the Adi Dravida subcaste, and a Dalit, and other ethnic identities. While these categories and identities may all be important for an individual at different moments, perhaps the most fundamental units of social organization that affects many aspects of everyday life is caste (Judge 2014: 8). At the village level I expect this to be a salient ethnic category that can be viably compared across villages and contexts. Incidentally, this position is also reflected in the influential work of Louis Dumont, who argued in Homo Hierachicus (1970) that no caste is undifferentiated, but has an internally nested structure that maps onto the large hierarchy.
} 
Back 1950). Third, "boundary making" homophily occurs if resources are distributed over social categories, such that members of one group can draw boundaries to restrict resource access to outsiders. This type of homophily is a fundamental form of social closure. Over time the homophily within these categories can strengthen as members of different categories develop mutual dispositions and identities. Fourth, "endogenous network mechanisms" including the sociability, reciprocity, and other balancing mechanisms such as triadic closure can produce ethnic homogeneity. In these cases it is not an "ethnic-group level mechanism" that produces homophily but a generalized network dynamic.

These mechanisms are difficult to disentangle without dynamic and longitudinal data where tie-formation (and dissolution) can be observed. It is likely that a combination of these factors drives any given instance of ethnic homophily. For example, people from a given group may associate frequently due to the availability of in-group contacts and propinquity, over time they may develop a sense of collective identity and develop stronger in-group preferences, and endogenous network mechanisms could lead to greater in-group cohesion over time. This study seeks to look at variation in the outcome of these processes: the level of homophily within a given group, context, and location at a single point in time.

Ethnic homophily is one aspect of what Rogers Brubaker calls ethnic "groupness." Social scientists, Brubaker argues, tend to conflate ethnic categories with ethnic groups, treating members of a given category as "substantial entities to which interests and agency can be attributed". This perspective leads to a representation of the world as "a multichrome mosaic 
of monochrome ethnic, racial, or cultural blocs" (2004: 8). We must recognize that "category members are not necessarily connected to one another, and relationally connected people need not belong to the same category" (Brubaker 2015: 16). Rather than taking ethnic groups as our fundamental unit of analysis we should treat "groupness as a contextually fluctuating conceptual variable" (Brubaker 2004: 11). Scholars of ethnicity must study the extent to which ethnic categories are associated with definite groups and how this relationship may vary across contexts. We cannot therefore assume a priori that people belonging to an ethnic category will form ties homophilously and exhibit groupness; nor should we should expect that the level of homophily will vary across locations and contexts. This paper assesses Brubaker's claim, using empirical data to measure the extent to which groupness, conceptualized a homophily, fluctuates across village and network contexts.

\subsection{Caste}

The archetypal form of the Indian caste system is the varna model, outlined in the ancient texts of the Manusmriti. People are divided into four mutually exclusive and hierarchically ordered varna categories and a fifth category that falls outside of the system. At the top of the hierarchy are the Brahmins, the priestly caste in charge of religious affairs, followed by the Kshatriyas, the warrior caste, whose role is to fight in times of war and govern in times of peace, below them are the Vaishyas, who are merchants, land-owners, and money-lenders, and at the bottom the Shudras, who provide labor and services to the higher castes. Below these groups, and outside of the varna system, are the lowest castes, who are often refered to as Dalits 
or Untouchables. They perform the activities considered most degrading such as slaughtering animals and tanning leather. The social hierachy is justifed by the religious concepts purity and pollution with Brahmins being considered the purest group and Dalits the most polluted. A Dalit is considered Untouchable since any member of a high caste who comes into contact with them is considered to be polluted and would have to undergo purification rituals to rectify this (Vaid 2014). There is also a sixth group of people in India who fall outside of these categories: the Adivasi are semi-nomadic people who live in remote areas and who were neither incorporated into traditional village society nor given a position in the caste system until the modern era. While not integrated into the varna system, like the Dalits, this group tends to be considered one of the lowest in the ritual hierarchy.

The varna model of class is a clear example of the groupism identified by Brubaker (2004). Members of each caste category form a bounded group that interacts with other bounded groups through a strictly delimited framework, governed by the rules of purity and pollution. Max Weber's The Religion of India exemplifies this position. Weber saw castes as "ethnic communities" of people linked by kinship and endogamous marriages, where each caste is "a closed status group" delimited by categorical membership. Each caste group then occupied a position within the hierachical caste order: "the caste structure transforms the horizontal and unconnected coexistences of ethnically segregated groups into a vertical system of super- and subordination" (Weber, quoted in Gerth and Mills 1958: 189).

While the varna framework is a useful preliminary model for understanding the "framework of hierarchy" between castes, jati or sub-caste, endoga- 
mous social groups, form the basic units of Indian social life (Srinivas 1989; Jodhka 2012). These kinship units vary greatly across India and do not map neatly onto the varna categories: "Thousands of jatis can exist for and across each varna, and thus there is no pan-Indian or standardized way of relating jati with varna" (Vaid 2014: 393). The reality of caste is therefore much more complex and dynamic than the simple varna model. The caste order itself was not immutable and the different jatis rose and fell within the varna order over time (Khilnani 1998: 19) and the relative positions of different groups have fluctuated (Srinivias 1966; Ainapur 1986: 3). Within each caste there is also a great deal of internal variation, including stratification by age, gender, and familial roles (Dumont 1970). Moreover, against the "groupist" tendencies described by Brubaker, Shah asserts that "all available evidence shows that hardly any caste was an undifferentiated and unified unit" (2010: 7).

Notwithstanding this flexibility and variation there are nonetheless strong boundaries between caste groups. Despite the flexibility of caste in the longue durée, an individual cannot change their caste identity and, at any given moment, each "caste is an exclusive cultural group and has distinctly marked boundaries in relation to other castes" (Judge 2014: 8). These boundaries are both structural - in terms of the social relations between members of different castes - and cultural - in terms of the attitudes and dispositions that govern these interactions (Wimmer 2013). Furthermore, it is also important to note that, despite the strong ethnic boundaries between caste groups, that the caste hierarchy is a system of interdependent relations. Srnivas (1980: 13) asserts that inter-caste relations within a village are "vertical" ties that 
can be economic, ritual, political, or civic. In each village or area there is typically one "dominant" caste which owns a sizeable amount of the local arable land, is numerically preponderant, and occupies a high position in the local ritual hierarchy (Srinivas 1966: 10). The prestige and power of the dominant caste is further secured through access to Western education, jobs in government administration, and income from relatives working in urban areas. The lower castes in each village are typically "tenants, servants, landless labourers, debtors and clients of the higher castes" (Srinivas 1980: 19). While the division of labor in Indian villages does not resemble the varna system, within each village the general contours of occupational and social stratification map onto positions within the caste order.

In contemporary India, the economic and cultural distances between different caste groups has narrowed. Srinivas $(1966 ; 1980 ; 1989)$ has argued that the caste system has experienced the three interlinked processes that have contributed to this change. First, sanskritization, as lower castes have gradually adopted the customs, rituals, and lifestyles of higher castes. Second, westernization, as the normative system imposed by over a century-and-ahalf of British colonial rule fundamentally altered ideology, values, and tastes in India. Third, modernization of social, economic, and political institutions has eroded traditional forms of social organization. Paradoxically, while the latter two changes have secularized Indian society, particularly among urban and educated groups, sanskritization has led to increasing religiosity among lower castes and tribes. Srnivas argues that these changes have led to increasing social mobility, an erosion of the traditional division of labor, and a weakening of adherence to the rules of purity and pollution. 
Despite these profound changes and instabilities, the caste order has remained resilient and is still the primary system of social organization in India, particularly in rural areas. The Indian government has implemented a series of legislative acts to attempt to mitigate the negative effects of caste, particularly for the most oppressed groups. Under British rule, the Government of India Act of 1935 led to the classification of certain caste groups, particularly those who were untouchable, as Scheduled Castes (SC). The practice of untouchability itself was banned under the Indian Constitution in 1950, although recent survey evidence suggests that it is still widely practiced (Thorat and Joshi 2015). A variety of laws have been put into place to give the SCs legal protection and affirmative action programs have been implemented to integrate them into modern Indian society (Jodhka 2012: 78-9). Protected groups receive reservations: quotas of reserved places in educational institutions and public sector jobs. These reservations also extend to the Adivasis, who are officially classified as Scheduled Tribes (ST) and constitute approximately 8 percent of India's population.

A series of commissions at both the state and national level were set up from the 1950s through to the 1970s in order to attempt to classify other disadvantaged groups based on economic, occupational, educational, and demographic criteria. Initially, 3743 such groups-constituting over forty percent of the population-were termed Other Backwards Classes (OBCs) by the Mandal Commission in 1978 and many continue have since been included (Hasan 2009; Jodhka 2012; Despande and Ramachandran 2014). The OBCs include former Shudras, the lowest caste in the varna system, and along with many of Indias religious minorities. Often these minorities were 
formerly Untouchables but once someone has converted to Islam or Christianity they can no longer be legally classified as Scheduled Castes since the Indian Constitution forbids affirmative action on the basis of religion (Hasan 2009: 196-223). Instead these groups are classified as OBCs on the basis of their jati. The OBC grouping is extremely heterogeneous, incorporating both caste groups that are truly disadvantaged and more middling groups including landowning castes (Deshpande and Ramachandran 2014). In some cases these reservations have actually created middle-classes out of certain OBC groups due to their increased access to state resources, leading to conflicts over reservation status (Hasan 2009).The remainder of the caste groups do not received any formal benefits or positive discrimination schemes from the government. They are known as the Forward Castes or General Class (GC). The majority of those who were members of one of the three dominant varna groups-Brahmins, Kshatriyas, and Vaishyas-fall into this category.

Despite these attempts to reform the caste structure and mitigate its negative consequences, for the most disadvantaged groups there are still many social inequalities and problems that exist. Judge (2014: 9) summarizes the contemporary situation: "Caste could be regarded as the single most structural element of the Indian society whose dynamic processes in the form of discrimination tend to be overwhelming." The cases are the bottom of the hierarchy are the "most deprived and excluded in terms of various indicators, such as choice of occupation, interaction, marriage, and food". It is a system of profound social exclusion, involving the discrimination, isolation, shaming, and deprivation of subordinate groups on the basis of their caste identity, along with other identities such as religion and gender (Thorat and Newman 
2007). It is therefore of fundamental importance to understand the degree to which caste continues to structure India village society, the extent to which this might vary among villages and contexts, and to understand the factors that help to perpetuate this system.

\subsection{Variation in caste homophily by village and context}

It is profoundly important that we are able to understand the dynamics of ethnic categories across villages; according to the 2011 Census of India, $68.84 \%$ of the population lives in villages (Judge 2014: 9). While much attention has been devoted to the study of individual villages, particularly by anthropologists, little work has been done to examine variation across different villages. I expect that, while remaining a salient category of social organization in all villages, it is likely that the strength of caste homophily will vary by village. Across villages there is heterogeneity in caste composition, the relative sizes of each caste, and on other individual attributes such as education, gender, age, and occupation.

The only similar work that has made cross-village comparisons of social structure is Entwistle et al.'s (2007) study of 51 villages in Nang Rong, Thailand. They argue that, even within the same region, villages are neither homogeneous nor isolated. They study the direct and indirect linkages between households within and between villages using two types of network: sibling ties and rice sharing. Their findings shows the presence of substantial vari-

ation in social networks across villages regarding density of ties and level of cohesion within villages, and the extent to which households are connected to those in other villages. They argue that researchers cannot generalize about the social structure of villages, even within a specific region. Other studies 
of multiple villages have not systematically compared network characteristics across villages, instead focusing on averages across villages (White and Watkins 2000) and patterns of diffusion within or between villages (Conley and Udry 2010; McCreesh et al. 2011; Banerjee et al. 2013; Kim et al. 2015).

Existing research has shown that ethnic homophily varies depending on the type of social relation (McPherson et al. 2001). Within the caste system, lower homophily is expected for the "vertical" economic, ritual, political, and civic ties that cross caste boundaries (Srinivas 1980). Under his formulation there is no space for purely social ties between members of different castes; instead the relationship between a high caste and a low caste individual often takes the form of a patron-client relationship, as the higher caste individual will lend money or lease land to the lower caste individual (Srinivas 1980). We should therefore expect that economic ties will be marked by lower levels of homophily than non-economic ties. The presence and strength of ritual, political, and civic ties are more difficult to generalize and is likely to vary across contexts. In the analysis below I examine a number of different types of networks in order to assess the extent to which caste homophily varies between economic and social ties.

\subsection{Caste in Karnataka}

Karnataka is the seventh largest of India's twenty-nine states and has a population of over sixty million people. The state is home to the linguistic community of Kannada language speakers, the state's official language. Many people also speak Urdu (in Muslim communities), Telugu, Tamil, Marathi, and a plethora of other languages and dialects. Whilst the state is majority Hindu, it is also home to a sizable number of religious minorities, the 
largest groups being Muslims and Christians. Bangalore, the state capital, is one of the main hubs of India's dynamic technological sector and a center of industrial activity, but the majority of the population lives in rural areas; over half of its residents are directly employed in agricultural production. In these areas many of the poorest people are members of the SCs and STs and in these communities problems with health and education are particularly acute. Evidence below is drawn from the 2005 Karnataka Human Development Report (Government of Karnataka 2006), a detailed report compiled by the state government to measure the impact of its development policies on issues related to gender, education, caste, agriculture, and social exclusion, along with research on caste in Karnataka by Indian social scientists.

The General Classes (GCs), who make up approximately one-third of the rural population, now play a lesser role in rural areas than is typical. In the early 20th century, an anti-Brahmin political movement made up of many of the lower and middling castes challenged Brahmin authority, leading many Brahmins to migrate to the cities (Shetty 1978; Jacob 2000). Jacob (2000) asserts that the groups that gained most from the displacement of the Brahmins were not the lowest castes, who were very active in the anti-Brahmin movement, but the Lingayats-a Shaivite sect that arose out of a movement against certain Hindu orthodoxies, including caste, in the 12th century but have since become integrated into the caste order (Weber 1958: 305; Srinivas 1986)-and the Vokkaligas, a numerically dominant agriculturalist caste. These groups not only assumed control of the arable land left by the Brahmins but also their symbolic status within the caste order. These factors, along with their numerical majority, has made these two jatis the politically 
dominant in rural Karnataka (Murahari 1989).

Since its introduction in 1979, OBC status and its associated reservations have been a source of political conflict in Karnataka (Pani 2010). The category includes many disadvantaged Hindu castes, often Shudras, along with the Muslim population and some former-Dalit Christians. They constitute $39 \%$ of the population of rural Karnataka, although only $16 \%$ of those below the poverty line. The majority of the OBCs are therefore much better placed than the SCs and the STs. Around 11\% of the population of Karnataka are Muslim OBCs. Overall Muslims tend to fare better than on the key poverty indicators than SCs and STs, earning more and achieving higher educational attainment, but they tend to be worse off than the average Hindu.

Scheduled Castes make up 16\% of Karnataka's population and are the "weakest in terms of political, economic, social and cultural resources" (Government of Karnataka 2005). Three-quarters continue to reside in rural parts of the state and, despite land reforms and reservation policies, the majority continue to live in poverty. Even for those who do own land it is often unviable as a sole source of income, forcing them to seek paid employment. Historically, the Dalit movement has been strong in Karnataka and the lower castes have organized effective social movements in opposition to these enduring inequalities (Shetty 1978; Yadav 2007). The most numerous Scheduled Caste group in the state are the Adi Karnataka (Mandal 1991), making up $34 \%$ of the SC population. Two other major groups that appear in the data used are the Bhovis who make up $10 \%$ and the Adi Dravidas who make up $7 \%$ of the states SC population. Educational attainment and literacy rates are low among these groups, preventing the majority of SCs from gaining 
higher status employment.

Finally, Scheduled Tribes make up around $6.5 \%$ of the population in Karnataka and share many of the disadvantages of the SCs. Their literacy rates, although improving, are well below the national average and are particularly low among females. ST males spend the least time in school of all caste groups. Although $57 \%$ of ST households do own some land it usually small plots and low-quality; $74 \%$ of it is unirrigated. The majority must therefore work as coolies and perform manual labor in order to support themselves and their families. These groups also inhabit poor quality and unsanitary dwellings, with four-fifths not having their own toilet or latrine.

\section{Data}

I use social network and attribute data from a sample of the inhabitants of seventy-five villages in Karnataka. The data were collected for a project led by economists Abhijit Banerjee and Esther Duflo at the Massachusetts Institute of Technology and Matthew Jackson and Arun G. Chandrasekhar of Stanford University. The National Science Foundation and the Abdul Latif Jameel Poverty Action Lab sponsored the project (Banerjee et al. 2013). All villages sampled are within a three-hour driving radius of Banglore. Using a census of all households in each village as a sampling frame, an in-depth survey was administered on a randomly selected sub-sample of households in each village, stratified by geographic sub-location and religion. This subsample is approximately one-third of the population of each village. The adult inhabitants of each targeted household were asked to give both attribute and relational information to the researcher. In total the survey 
yielded data for 16,908 individuals, including social network data. Each respondent was asked name-generator questions relating to their social, material, ritual, and kinship ties. In total I examine eight different types of relationships, which I now discuss in turn.

There are four name-generator questions relating to social and advice relationships. There are two questions asking about visitation: which alters' households does the ego regularly visit and which alters regularly visit the ego's household. These questions are a good proxy for personal relationships such as friendships. There are also two questions about advice. The first asks, "If you had to make a difficult personal decision, whom would you ask for advice?". The second asks the ego to name the alters who they regularly give advice to. These two questions are somewhat analogous to the "important matters" question in the General Social Survey, which Marsden (1987) argues gives a relatively accurate representation of an ego's discussion network-the people with whom one converses frequently. It is important to recognize, however, that the macro-social setting strongly influences the micro-social associations evoked by particular questions (Bearman and Parigi 2004). Since we do not know exactly how participants interpreted the question nor how it was translated into their native languages we cannot be completely certain about what precise relations the social networks actually represent.

There are four questions regarding borrowing and lending. The first two questions relate to money: "If you suddenly needed to borrow Rs.50 for a day, who would you ask?" and "Who do you trust enough, that if he/she needed to borrow Rs.50 for a day you would lend it to him/her?". This is a small but by no means insignificant amount of money; at the time of the 
survey it was equivalent to roughly $\$ 1$ and the per capita daily income was approximately $\$ 3$ or less. These questions may capture both lending of money between friends and acquaintances within the same caste and the patronclient money-lending practices that occur between high and low castes. The second two questions ask whom an ego would go to and which alters would come to an ego if they needed to borrow kerosene or rice, two everyday staples. Unfortunately the researchers did not ask about these two items separately, since the sharing of food is one of the key aspects of the caste based rules on pollution and purity: Low caste people were generally prohibited from sharing or giving food or water to people of higher castes, particularly to those at the top of the hierarchy. To receive something from these groups would be seen as polluting by the pure higher castes (Dumont 1970). While this question should give a good indication of whether people are socially close enough to share resources with one another it will likely exhibit higher caste homophily due to the inclusion of food. Cumulatively, these four relations capture the material support networks that exist within these villages outside of the more formal economy.

There is also a ninth matrix containing information on kinship ties. This contains information on a respondent's "close relatives" living in the village, along with other members of their household. I use this data to differentiate between kin and nonkin ties. I expect that, given the strict rules of caste endogamy, that kinship ties will be marked by extremely strong caste homophily. The inclusion of these ties would therefore bias upwards any estimates of group-level homophily. I therefore use the kinship matrix to remove any ties between kin from the above matrices by matrix subtraction. 
The data also include individual-level attributes for all the respondents for whom we have ego-network data. Table 1 shows the averages for key variables across the 75 villages in the sample. The demographic variables show that the average age is 39 and that there are more females than males in each village, possibly because males are more likely to leave to work in urban areas. Overall education rates are low; on average people have either only attended primary school or have some high school education. Turning to caste we see that the majority of people are either SC (25\%) or OBC (56\%). STs and GCs are not present in every village and their oveall populations are far lower, although this varies between villages. Only $4 \%$ of the sample are Muslims and $<0.5 \%$ identify as Christian. Given the number of languages spoken in the state it is perhaps unsurprising that $62 \%$ of respondents are multilingual, although this varies greatly by village. Only 56\% of the respondents are native to (were born in) their current village. This is predominantly due to patterns of caste endogamy and village exogamy; women tend to marry men within their caste group but outside of their kinship group, typically meaning that they must marry a man residing in another village. The bride is expected to move to her husbands village, either into his household or often that of his parents.

Turning to the social network statistics I show degree statistics split by kin and nonkin. These statistics are based on the sum of the social relations within each village; if two people are tied on any one of the eight relations classified above then they share a tie, if they are also tied in the kin matrix then the tie is marked as a kinship tie. We see that people tend to direct and receive slightly more ties to nonkin than kin. The average outdegree does not 
equal the average in-degree because I have included ties directed to people who did not participate in the survey within these measures (although they are not included in the following analysis since I do not have any demographic data for these alters).

\section{Methods}

Although the fundamental unit of social life in rural India is the jati, it is difficult to use this level of granularity across multiple cases: each village has many different jatis, most jatis only occur in a subset of villages, and the data are not standardized, so multiple spellings exist for each group. In the interest of comparability and parsimony it is therefore necessary to use more general categories. Each individual in the data belongs to one of the four aforementioned caste categories: Scheduled Tribe, Scheduled Caste, Other Backwards Caste, and General Class. Given our knowledge of the OBC dominance and the relatively small populations of ST and GC in rural Karnataka it is useful to simplify this schema by collapsing these into two categories, high caste and low caste. Given their similar status we group SCs with STs are grouped together as "low caste" and OBCs with GCs together as "high caste". I do not imply any normative judgment by the terms high and low but merely use them to denote the relative positions of each group within the caste order. Ethnic categories operate in a nested fashion (Wimmer 2008; 2013); an individual is simultaneously an Adi Karnataka, a Scheduled Caste, a Dalit, and a member of a low-status caste. Using the higher-order categorization of high-low caste allows for a more parsimonious analysis that facilitates comparison across network types and villages. 
Table 1: Descriptive statistics, averaged across villages

\begin{tabular}{l|llll}
\hline Variable & Mean & SD & Min. & Max. \\
\hline Demographic & & & & \\
Avg. age & 39.07 & 1.41 & 35.78 & 42.40 \\
Avg. years of education & 5.02 & 0.98 & 2.28 & 6.72 \\
\% Female & 0.55 & 0.02 & 0.51 & 0.59 \\
\% Scheduled Tribe & 0.06 & 0.09 & 0 & 0.44 \\
\% Scheduled Caste & 0.25 & 0.17 & 0 & 0.97 \\
\% Other Backwards Caste & 0.56 & 0.21 & 0.04 & 0.96 \\
\% General Class & 0.12 & 0.17 & 0 & 0.85 \\
\% Muslim & 0.04 & 0.08 & 0 & 0.42 \\
\% Multilingual & 0.62 & 0.33 & 0 & 0.98 \\
\% Native to village & 0.56 & 0.05 & 0.24 & 0.70 \\
\% Worked in past week & 0.63 & 0.07 & 0.40 & 0.86 \\
Social network & & & & \\
Average nonkin indegree & 1.94 & 0.50 & 1.07 & 3.52 \\
Average nonkin outdegree & 3.76 & 0.66 & 2.63 & 5.77 \\
Average kin indegree & 1.72 & 0.35 & 1.091 & 2.62 \\
Average kin outdegree & 3.13 & 0.50 & 2.09 & 4.45 \\
Household & & & & \\
\% Has lavatory & 0.30 & 0.13 & 0.02 & 0.59 \\
\% Has electricity & 0.94 & 0.04 & 0.83 & 1 \\
Number of residents sampled & 225.44 & 70.74 & 94 & 413 \\
\hline Number of villages & 75 & & & \\
\hline
\end{tabular}


To measure homophily, I use the Coleman Homophily Index (CHI) (Coleman 1958; Bojanowski and Corten 2014). The measure is designed for directed networks and is based on the null hypothesis that network ties are formed according to random-mixing, where individuals will direct ties to others independently of their category membership. Any deviation from random-mixing signals the presence of either homophily (in-group preference) or heterophily (out-group preference).

Coleman's index accounts for two important network features, variation in outdegree and differences in population proportions. First, it is important that we account for differences in outdegree - the number of outgoing ties a given person directs to other people in the network - since this may have an effect on our outcome. For example, a particularly gregarious individual may have an expansive social network that includes both in-group and outgroup members. Second, the relative population proportion of each subgroup within a network is expected to effect the level of homophily in a network. Under the random-mixing assumption we expect that the number of ties directed to a group will be proportional to the group size. For example, if $60 \%$ of nodes belong to group A and $40 \%$ of nodes belong to group B then under the random-mixing assumption we would expect that any given member of group A to direct $60 \%$ of their ties to members of their own group and $40 \%$ of ties to members of the other group. Combining these two variables, under the assumption of random mixing we would expect the number of in-group ties for an individual to equal their out-degree multiplied by the proportion of in-group members in the network. McPherson et al. (2001) call this "baseline homophily". Any increase in the number of in- 
group ties beyond this baseline signals that tie formation is not random and that group membership is likely influencing tie formation. This is termed "in-breeding homophily" (McPherson, Smith-Lovin, and Cook 2001) and all discussion of homophily in this paper refers to this variant.

To measure the in-breeding homophily we must first calculate $\widehat{\theta_{k}}$, the expected number of ties within group $k$ under the random-mixing assumption:

$$
\widehat{\theta_{k}}=\sum_{i \in G_{k}} \delta_{i} \frac{s_{k}-1}{N-1}
$$

The expected value for the $i$ th node in group $k$ is simply $i$ 's outdegree, $\delta_{i}$, multiplied by the proportion of nodes in the network that belong to group $k$. The sum of these values for all $i \in G_{k}$ gives us the expected number of within-group ties for group $k$.

$$
C H I= \begin{cases}\frac{\theta_{k}-\widehat{\theta_{k}}}{\sum_{i \in G_{k}} \delta_{i}-\widehat{\theta_{k}}} & \text { if } \theta_{k} \geqslant \widehat{\theta_{k}} \\ \frac{\theta_{k}-\widehat{\theta_{k}}}{\widehat{\theta_{k}}} & \text { if } \theta_{k}<\widehat{\theta_{k}}\end{cases}
$$

The CHI for group $k$ is then calculated based upon the relationship between the expected number of within-group ties, $\widehat{\theta_{k}}$, and the observed value, $\theta_{k}$, which is simply the number of directed ties between members of group $k$. A CHI equal to zero that the expected value is equal to the observed value; this indicates that the level of homophily does not exceed the baseline homophily and therefore that there is no in-breeding homophily. A score greater than zero indicates in-breeding homophily, with +1 indicating perfect homophily where all ties are within-group. Conversely, a CHI below indicates fewer in-group ties than expected - less than baseline homophily- 
with a score of - 1 indicating perfect heterophily where all ties are to out-group members. This would be the case if the groups were sex and the relations were heterosexual sexual relationships; all ties would be male-to-female or female-to-male. A CHI is calculated for both high and low caste groups in every network in every village in the sample $(2 \times 8 \times 75=1200 \mathrm{CHI}$ scores $)$.

\section{Results}

\subsection{Differences across villages}

Overall there were 73 villages containing members of both high and low caste groups. The average homophily scres for each group-relation are reported in Table 2. Across both groups and all relations we see that there is a full range of scores from perfect homophily to perfect heterophily. To assess the variation across villages I first calculated the within-village average homophily score for each group across all types of relations. On average, both high and low groups show strong homophilic tendencies, although the strength of homophily is greater among the high caste groups, with a score of 0.70. A t-test confirms the difference between high and low caste groups is statistically significant $(\mathrm{p}<0.007)$. If we look at the minimum and maximum scores we see that, on average, all high caste groups showed an in-breeding preference, as indicated by positive homophily scores. For low caste groups the average values range between -0.75 , indicating strong heterophily, and 0.94, extreme homophily. Only two villages showed a tendency towards heterophily across all relations. In terms of differences between villages the level of variance is greater for low castes than high caste, with variance scores of 0.073 and 0.042 respectively. Overall this shows that, on average, both high 
Table 2: Average Coleman Homophily Index by Network Type

\begin{tabular}{|c|c|c|c|c|}
\hline Network type & Mean & $\mathrm{SD}$ & Min. & Max. \\
\hline \multicolumn{5}{|l|}{ Low caste } \\
\hline Borrow money & 0.40 & 0.37 & -1 & 0.95 \\
\hline Lend money & 0.60 & 0.30 & -1 & 1 \\
\hline Borrow kerosene or rice & 0.67 & 0.30 & -1 & 1 \\
\hline Lend kerosene or rice & 0.63 & 0.31 & -1 & 1 \\
\hline Visit alter's home & 0.58 & 0.34 & -1 & 1 \\
\hline Alters visit ego's home & 0.55 & 0.29 & -1 & 1 \\
\hline Help alter with decision & 0.61 & 0.22 & 0 & 1 \\
\hline Give advice to alter & 0.70 & 0.29 & -1 & 1 \\
\hline Average for all types & 0.59 & 0.27 & -0.75 & 0.94 \\
\hline \multicolumn{5}{|l|}{ High caste } \\
\hline Borrow money & 0.69 & 0.29 & -1 & 1 \\
\hline Lend money & 0.60 & 0.24 & -0.02 & 1 \\
\hline Borrow kerosene or rice & 0.67 & 0.25 & -0.09 & 1 \\
\hline Lend kerosene or rice & 0.72 & 0.25 & -0.15 & 1 \\
\hline Visit alter's home & 0.66 & 0.24 & -0.09 & 1 \\
\hline Alters visit ego's home & 0.68 & 0.23 & -0.05 & 1 \\
\hline Help alter with decision & 0.82 & 0.17 & 0.19 & 1 \\
\hline Give advice to alter & 0.76 & 0.18 & 0.19 & 1 \\
\hline Average for all types & 0.70 & 0.20 & 0.06 & 0.98 \\
\hline Number of villages & 73 & & & \\
\hline
\end{tabular}






Figure 1

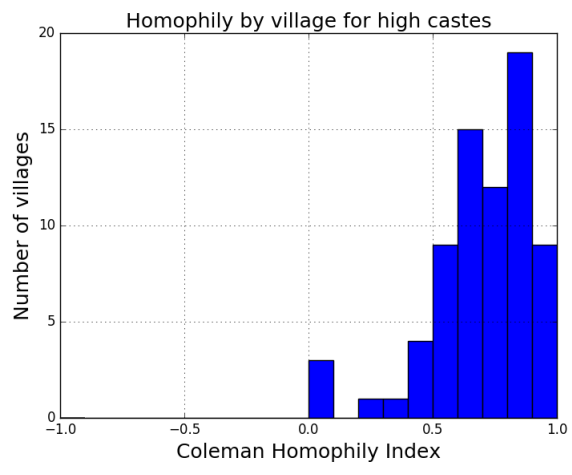

Figure 2

and low caste groups tend to be strongly homophilous across the majority of villages. High castes in particular tend to show more extreme tendencies towards homophily than low caste groups.

\subsection{Differences across contexts}

To assess the degree to which there is variation across network contexts within each village I use a oneway-ANOVA. Across all villages this allows me to assess if there are significant differences between network contexts within each village. For both low and high castes there are significant differences between contexts, with F-statistics of 6.21 and 6.07 respectively. Returning to Table 2 we see that for both high and low groups there are differences between the homophily scores for each network context. For low caste groups the homophily score is particularly low for borrowing money and particularly high for borrowing kerosene or rice and giving advice. For high caste groups the homophily, on average, is lowest for lending money and is particularly high for helping with decisions and giving advice. This evidence appears to support the theory that there are few social ties between low and high 
caste groups but that vertical ties exist for economic purposes. Moreover, the results also suggest that this pattern does not hold for the exchange of rice and kerosene, which tends to be highly homophilous. I now look at these difference in greater detail.

To understand if the differences between the levels of homophily for borrowing and lending money within each group are statistically different I compute t-tests to compare the mean values. For low castes borrowing money tends to be far less homophilous than lending money, suggesting that they tend to lend within group but borrow from upper castes. It is important to note that both relations still show strong homophilic tendencies but that these tendencies are significantly lower for borrowing than lending $(\mathrm{p}<0.001)$. For high castes the opposite is true: they are significantly less homophilous in lending money than borrowing money $(\mathrm{p}<0.001)$. Within each caste there is clearly money-lending, but between castes there is a tendency for the practice appears to be unidirectional; high castes make loans to low castes. This provides evidence of dependency between the lower castes and the "dominant castes" within the villages studied. Turning to kerosene and rice we see that both groups tend to be much more homophilous. Low caste groups are significantly more homophilous in terms of whom they both borrow rice and kerosene from $(p<0.0001)$ and whom they lend it to $(p<0.006)$. For high caste groups there is no significant difference in homophily wit regards to borrowing rice and kerosene or money; they tend to be strongly homophilous with respect to both. There are, however, significantly less homophilous in terms of lending money than the other commodities $(\mathrm{p}<0.0001)$. 


\subsection{Correlates of homophily}

In order to better understand why there might be differences in homophily between groups, villages, and contexts I now conduct multivariate analyses. It is important to note that due to the cross-sectional nature of these data I cannot make causal claims about the relationship between the level of homophily and other covariates, although these models do provide some suggestive conclusions and identify issues that should be looked at more closely in future research.

I run an OLS regression to predict the average level of homophily within each village-group, controlling for the average demographic variables for each village. The results are shown in Table 3. Although the small number of villages limits the statistical power of the analysis there are still a number of variables that are significant predictors of the average level of homophily. Interestingly the average age, education level, and gender of respondents in each village is uncorrelated with the level of caste homophily. It appears that these individual level attributes vary within each group but do not have an effect on the general patterns of relations between each group.

The percentage of low caste individuals in a given village has different relationships to the level of caste homophily for low and high caste groups. For low caste groups, an increase in the percentage of SCs or STs (relative to the reference group of $\mathrm{OBCs}$ ) is associated with a decrease in the average level of caste homophily. For high caste groups it has the opposite relationship,

a higher proportion of these groups is associated with an increase in caste homophily.

Net of other variables, the percentage of respondents native to a village 
Table 3: OLS regression predicting average homophily

\begin{tabular}{|c|c|c|}
\hline VARIABLES & $\begin{array}{l}(1) \\
\text { Low caste }\end{array}$ & $\begin{array}{l}(1) \\
\text { High caste }\end{array}$ \\
\hline Avg. age & $\begin{array}{l}0.010 \\
(-0.015)\end{array}$ & $\begin{array}{l}0.021 \\
(-0.014)\end{array}$ \\
\hline Avg. years of education & $\begin{array}{l}-0.002 \\
(-0.027)\end{array}$ & $\begin{array}{l}0.024 \\
(-0.032)\end{array}$ \\
\hline$\%$ Female & $\begin{array}{l}0.087 \\
(-1.338)\end{array}$ & $\begin{array}{l}-0.221 \\
(-1.470)\end{array}$ \\
\hline$\%$ ST & $\begin{array}{l}-0.568^{*} \\
(-0.333)\end{array}$ & $\begin{array}{l}-0.675 \\
(-0.435)\end{array}$ \\
\hline$\% \mathrm{SC}$ & $\begin{array}{l}-0.264^{* *} \\
(-0.124)\end{array}$ & $\begin{array}{l}0.424^{* *} \\
(-0.178)\end{array}$ \\
\hline$\% \mathrm{GC}$ & $\begin{array}{l}-0.11 \\
(-0.17)\end{array}$ & $\begin{array}{l}0.113 \\
(-0.19)\end{array}$ \\
\hline$\%$ Muslim & $\begin{array}{l}-0.020 \\
(-0.307)\end{array}$ & $\begin{array}{l}-0.325 \\
(-0.283)\end{array}$ \\
\hline$\%$ Multilingual & $\begin{array}{l}-0.116 \\
(-0.085)\end{array}$ & $\begin{array}{l}0.136 \\
(-0.087)\end{array}$ \\
\hline$\%$ Native to village & $\begin{array}{l}1.426^{* * *} \\
(-0.451)\end{array}$ & $\begin{array}{l}1.060^{* *} \\
(-0.514)\end{array}$ \\
\hline$\%$ Worked last week & $\begin{array}{l}-0.119 \\
(-0.254)\end{array}$ & $\begin{array}{l}-0.13 \\
(-0.289)\end{array}$ \\
\hline$\%$ Electricity in house & $\begin{array}{l}0.126 \\
(-0.515)\end{array}$ & $\begin{array}{l}-0.881^{*} \\
(-0.464)\end{array}$ \\
\hline$\%$ Latrine in house & $\begin{array}{l}0.185 \\
(-0.219) \\
\end{array}$ & $\begin{array}{l}0.071 \\
(-0.211) \\
\end{array}$ \\
\hline Constant & $\begin{array}{l}-0.43 \\
(-1.125)\end{array}$ & $\begin{array}{l}-0.005 \\
(-1.208)\end{array}$ \\
\hline Observations & 71 & 73 \\
\hline R-squared & 0.41 & 0.51 \\
\hline
\end{tabular}


has a strong relationship with the level of homophily. A high level of natives indicates that there are few people marrying into the village. Finally, the percentage of households with electricity is negatively associated with the level of homophily among high caste groups.

\section{Discussion and Conclusion}

The results show that caste remains an enduring institution across all the villages studied. While there is variation in the level of homophily across village, group, and network context there is generally a strong preference for tie-formation within one's caste group. Although I have only analyses a rough high-low division according to each person's official status I expect that analysis at the fine-grained level of the subcaste or jati would show more complexity within each group but the same general pattern.

There is strong evidence in support of Brubaker's (2004) claim that groupness is "a contextually fluctuating variable". The results show that groupness varies both depending on the group we study - with higher castes tending to show stronger tendencies towards homophily than lower castes - and the network context - as social relations exhibit high levels of homophily but economic relations show evidence of patterns of inter-group exchange. While social relations tend to be horizontal, that is, within-caste, we see that, un-

der certain conditions, there are also vertical ties of economic dependency between castes.

Although we cannot model the exact tie-formation mechanism with crosssectional data the regression analyses allow us to observe the correlates of homophily. It appears that a larger presence of lower caste groups is asso- 
ciated with higher levels of homophily. There are two likely explanations for these differences: First, since SCs and STs are marginalized groups, a high proportion of them will likely indicate a situation where they are more dependent on the upper castes, leading to less homophily. Second, if social ties between high and low castes are infrequent then a high proportion of SCs will cause the upper castes to form denser within-group ties as they will not form ties to Untouchables. The percentage of villagers who are native to their current village also strongly predicts homophily. This may indicate that there are large endogamous kinship groups in each village who are inbreeding both sexually and with regards to other types of social relations. These findings suggest that villages with larger populations of lower status people and low mobility may have particularly acute problems of segregation. The finding that the percentage of households with electricity weakens the homophily among higher castes is suggestive of effect of modernization and urbanization on weakening the salience of caste (Srinivas 1966).

While this paper has focused on caste in India, the issue of ethnic and racial homophily and its implications - segregation, isolation, social stratification, conflict - affects almost all societies. For example the racial order in the United States mirrors these dynamics, as blacks and whites tend to live in different places and form friendships and social ties to other members of the same racial category. Often when cross-racial ties do exist they are related to economic, rather than social, exchanges. Massey and Denton (1993: 131) argue that strong social and spatial segregation produces "a powerful feedback loop between individual and collective behaviour", leading to the clustering of social ills within a particular spatial area and the population 
that occupies it. This ultimately reproduce the structural conditions that perpetuate their low status.

It is extremely important for social scientists and policy makers to understand the relationships between ethnic homophily and other factors, both structural and individual. To do this it is necessary to gather longitudinal data in order to observe the process of network formation and dissolution and to understand how such systems emerge. Harrison White (2008: 53) argues that there is a tendency in social life to "generate groups out of categories", yet it appears that only certain social categories are salient in terms of the patterning of social relations. Moreover, we could also observe the opposite process - the formation of categories out of groups - as people clustered together in social space develop a collective identity and a unique repertoire of communicative practices (Wimmer 2013). Understanding these processes is crucial to the explanation of the relationship between social categories and social structures.

[1] Ainapur, L. S. 1986. The Dynamics of Caste Relations in Rural India. Jaipur: Rawat Publications

[2] Banerjee, Abhijit, Arun G. Chandrasekhar, Esther Duflo, and Matthew O. Jackson. 2013. "The Diffusion of Microfinance." Science 341(6144): 1236498.

[3] Bearman, Peter, and Paolo Parigi. 2004. "Cloning Headless Frogs and Other Important Matters: Conversation Topics and Network Structure." Social Forces 83(2): 535-557. 
[4] Bojanowski, Michal, and Rense Corten. 2014. "Measuring segregation in social networks." Social Networks 39: 14-32.

[5] Brubaker, Rogers. 2004. Ethnicity without Groups. Cambridge, MA: Harvard University Press.

[6] Brubaker, Rogers. 2015. Grounds for Difference. Cambridge, MA: Harvard University Press.

[7] Coleman, James. 1958. "Relational Analysis: The Study of Social Organizations with Survey Methods." Human Organization 17(4): 28-36.

[8] Conley, Timothy G., and Christopher R. Udry. "Learning about a new technology: Pineapple in Ghana." The American Economic Review: 35-69.

[9] Deshpande, Ashwini, and Rajesh Ramachandran. 2013. "How Backward are the Other Backward Classes? Changing Contours of Caste Disadvantage in India." Centre for Development Economics, Working Paper No. 233, available online at: <http://www.cdedse.org/pdf/work233.pdf>

[10] Dumont, Louis. 1970. Homo Hierachicus: An Essay on the Caste System, translated by Mark Sainsbury. Chicago, IL: The University of Chicago Press.

[11] Entwistle, Barbara, Ronald R. Rindfuss, Katherine Faust, and Toshiko Kaneda. 2007. "Networks and Contexts: Variation in the Structure of Social Ties." American Journal of Sociology 112(5): 14951533.

[12] Gerth, H. H., and C. Wright Mills. eds. From Max Weber: Essays in 
sociology, translated by H.H. Gerth and C. Wright Mills. Oxford: Oxford University Press.

[13] Hasan, Zoya. 2009. Politics of Inclusion: Caste, Minorities, and Affirmative Action Oxford: Oxford University Press.

[14] Festinger, Leon, Kurt W. Back, and Stanley Schachter. 1950. Social Pressures in Informal Groups: A Study of Human Factors in Housing. New York, NY: Harper.

[15] Jacob, T. G. 2000. Reflections on the Caste Question, an overview of Tamilnadu, Karnataka 83 Keralam. Bangalore: Nesa.

[16] Jodkha, Surinder S. 2012. Caste. Oxford: Oxford University Press.

[17] Judge, Paramjit S. ed. 2014. Mapping Social Exclusion in India: Caste, Religion and Borderlands. Cambridge: Cambridge University Press.

[18] Government of Karnataka. 2006. Karnataka Human Development Report. Bangalore: Government of Karnataka.

[19] Kim, David A., Alison R. Hwong, Derek Stafford, D. Alex Hughes, A. James O'Malley, James H. Fowler, and Nicholas A. Christakis. 2015. "Social network targeting to maximise population behaviour change: a cluster randomised controlled trial." The Lancet 386(9989): 145-153.

[20] Khilani, Sunil. 1998. The Idea of India. New York, NY: Farrar Straus Giroux. 
[21] Mandal, Debabrata. 1991. "The Adikarnataka: An agrarian Scheduled Castes of Karnataka", in H. C. Upadhyay ed. Scheduled Caste and Scheduled Tribes in India: A Socio-Economic Profile. New Delhi: Anmol Publications, 282-292.

[22] Marsden, Peter V. 1987. "Core discussion networks of Americans." American Sociological Review 52(1): 122-131.

[23] Marsden, Peter V. 1988. "Homogeneity in confiding relations." Social Networks 10(1): 57-76.

[24] Massey, Douglas S., and Nancy A. Denton. 1993. American Apartheid and the Making of an Underclass. Cambridge, MA: Harvard University Press.

[25] McCreesh, Nicky, Lisa G. Johnston, Andrew Copas, Pam Sonnenberg, Janet Seeley, Richard J. Hayes, Simon DW Frost, and Richard G. White. 2011. "Evaluation of the role of location and distance in recruitment in respondent-driven sampling." International Journal of Health Geographics $10(56)$.

[26] McPherson, Miller, Lynn Smith-Lovin, and James M. Cook. 2001. "Birds of a feather: Homophily in social networks." Annual Review of Sociology: 415-444.

[27] Pani, Narendar. 2010. "Reservations, Exclusion, and Conflict: Some Insights From Mandal and Mysore." India Review, 9(4): 397-424.

[28] Shah, A. M. 2010. The Structure of Indian Society: Then and Now. New Delhi: Routledge. 
[29] Shetty, Rajshekar V.T. 1978. Dalit Movement in Karnataka. Madras: The Christian Literature Society.

[30] Srinivas, M.N. 1966. Social Change in Modern India. Berkeley, CA: University of California Press.

[31] Srinivas, M.N. 1980. India: Social Structure. New Delhi: Hindustan Publishing Corportation (India).

[32] Srinivas, M.N. 1989. The Cohesive Role of Sanskritization and Other Essays. New Delhi: Oxford University Press.

[33] Thorat, Amir, and Omkar Joshi. 2015. "The Continuing Practice of Untouchability in India: Patterns and Mitigating Influences." Paper presented at the annual meeting of the Population Association of America, San Diego, California, April 30th-May 2nd.

[34] Thorat, Sukhadeo, and Katherine S. Newman. 2012. Blocked by caste: economic discrimination in modern India. Oxford: Oxford University Press.

[35] Vaid, Divya. 2014. "Caste in Contemporary India: Flexibility and Persistence." Annual Review of Sociology 40: 391-410.

[36] White, Kevin, and Susan Cotts Watkins. 2000. "Accuracy, stability and reciprocity in informal conversational networks in rural Kenya." Social Networks 22(4): 337-355.

[37] Weber, Max. 1958. The Religion of India: The Sociology of Hinduism 
and Buddhism, translated by H.H. Gerth and Don Martindale. Glencoe, IL: The Free Press.

[38] White, Harrison. 2008. Identity and Control: How Social Formations Emerge, 2nd edition. Princeton, NJ: Princeton University Press.

[39] Wimmer, Andreas. 2008. "The Making and Unmaking of Ethnic Boundaries: A Multilevel Process Theory." American Journal of Sociology 113(4): 970-1022.

[40] Wimmer, Andreas. 2013. Ethnic Boundary Making: Institutions, Power, Networks. New York, NY: Oxford University Press.

[41] Yadav, Manohar. 2007. "Dalit Movement in Karnataka: A Critical Analysis of its Past and Present Realities," in M. Thangaraj ed. Dalit Movements in South India: Problems and Challenges. Chennai: University of Madras. 